\title{
ОЦЕНКА БЕЗОПАСНОСТИ ВЕДЕНИЯ ГОРНЫХ РАБОТ НА УЧАСТКАХ С РАЗВИТЫМИ В ВОДОЗАЩИТНОЙ ТОЛЩЕ ЗОНАМИ ПРИРОДНОЙ НАРУШЕННОСТИ
}

\author{
И.С. ЛОМАКИН \\ Горный институт УрО РАН, г. Пермь
}

\begin{abstract}
Аннотация. Анализ изменения напряженно-деформированного состояния водозащитной толщи при реализации параметров системы разработки на Верхнекамском месторождении калийных солей играет важную роль для обеспечения безопасного ведения горных работ. Особое значение он приобретает вблизи районов с развитыми в водозащитной толще зонами природной нарушенности. Целью представленной работы являлась геомеханическая оценка текущего состояния водоупорных пластов вблизи области аномального строения водозащитной тощи. Расчеты базировались на математическом моделировании изменения напряженно-деформированного состояния горных пород. Численная реализация осуществлялась в упругопластической постановке для условий плоского деформированного состояния методом конечных элементов. Результаты геомеханического моделирования позволили оценить достаточность принятых мер охраны и возможные последствия при их нарушении.
\end{abstract}

Ключевые слова: водозащитная толща, напряженно-деформированное состояние, нарушенность горных пород. техногенная трещиноватость, метод конечных элементов.

Одной из задач безопасного ведения горных работ на рудниках Верхнекамского месторождения калийных солей является сохранность сплошности водозащитной толщи (В3Т), отделяющей продуктивные пласты калийных солей от водоносных горизонтов.

Осенью 2017 года при отработке пласта АБ было обнаружено поступление рассолов в выработанное пространство, сопровождающееся газовыделением. В связи с этим для оценки горно-геологической ситуации на данном участке выполнен комплекс геологических и геофизических исследований, по результатам которых выявлена развитая область аномального строения ВЗТ в виде «купола», в пределах которой ведение очистных работ запрещено. На уровне кровли ВЗТ максимальное простирание аномальной зоны в широтном и меридиональном направлениях оценивается в 450-500 м. На уровне пласта АБ - в широтном направлении составляет около 80-100 м, в меридиональном 40-50 м. Целью геомеханических исследований являлась оценка достаточности принятых мер охраны В3Т на данном аномальном участке шахтного поля, а также изменение напряженно-деформированного состояния налегающей толщи в случае формирования здесь выработанного пространства. В данной работе представлены результаты расчетов, полученные вдоль геомеханического профиля меридионального простирания, пролегающего через область рассолопроявления. Принципиальная схема расчета показана на рис. 1.

Для анализа деформирования подработанного массива во времени использовался реологический подход, основанный на математическом описании прогнозных графиков нарастания оседаний земной поверхности [1].

В рамках линейной теории наследственной вязкоупругости принималось, что вертикальные смещения дневной поверхности изменяются во времени, согласно соотношению:

$$
v(t)=v_{0}\left(1+\int_{0}^{t} K(\tau) d \tau\right)=v_{0}[1+\Phi(t)],
$$

где $v_{0}$ - упругие смещения, связанные с формированием выработанного пространства; $K(t-\tau)$-функция влияния напряжения $\sigma(\tau)$ на деформацию в момент времени $t$, 
$\Phi(t)$ - функция ползучести. Поскольку реальные графики нарастания оседаний определяются разностью полных и упругих смещений, то

$$
\eta(t)=v(t)-v_{0}=v_{0} \Phi(t)
$$

Функция ползучести $\Phi(t)$ определяется фактическими или прогнозными графиками нарастания оседаний земной поверхности. Ввиду малой истории наблюдений по профильным линиям определение функции ползучести $\Phi(t)$ основывалось на построении прогнозных графиков нарастания оседаний земной поверхности согласно нормативному документу [2].

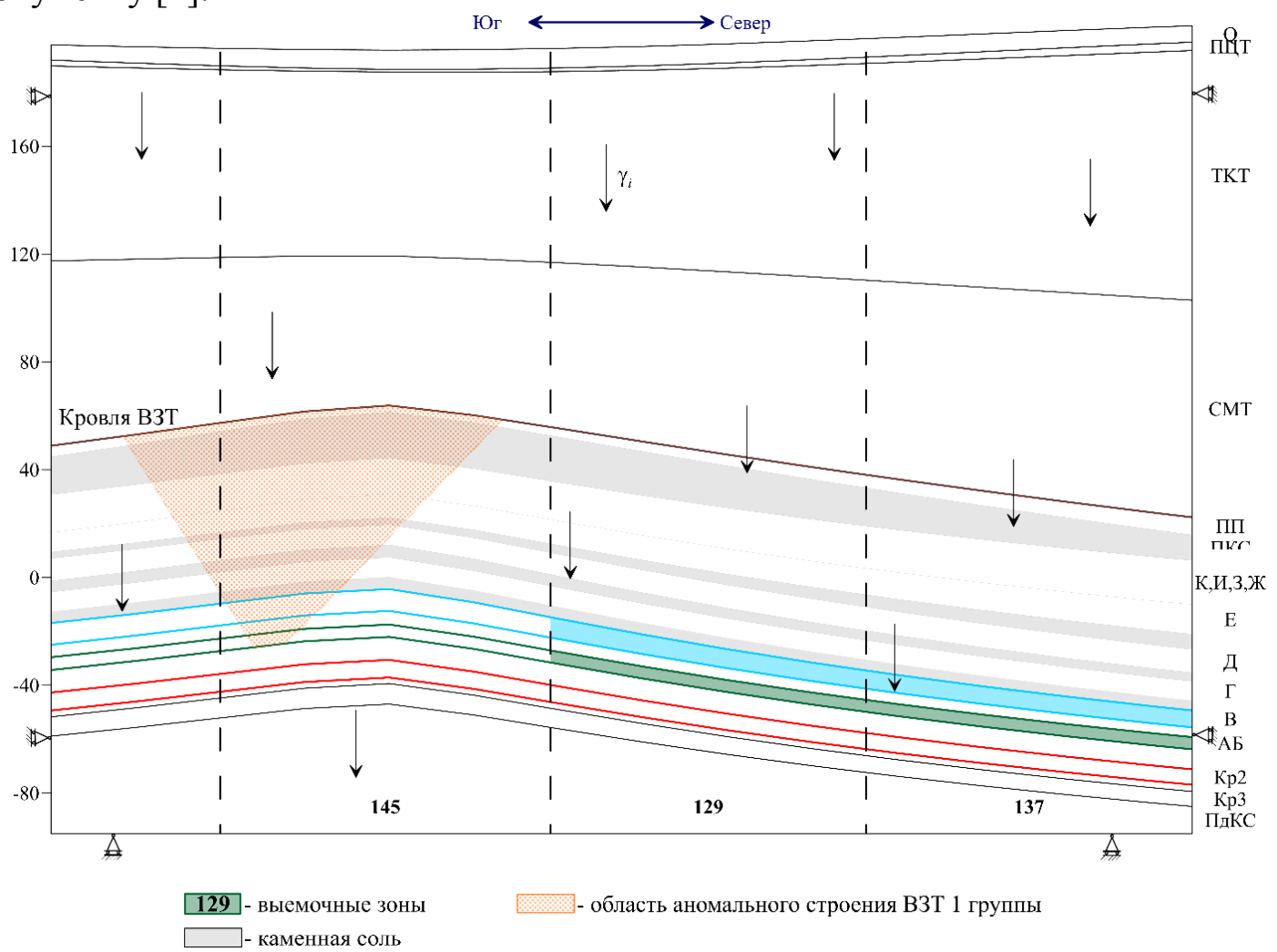

Рис. 1. Принципиальная схема расчета

В качестве определяющего уравнения нелинейной связи напряжений и деформаций использовалась идеальная упругопластическая модель, которая является обобщением упругой и жесткопластической среды с внутренним трением. Условием нарушения сплошности ВЗТ за счет образования трещин сдвига являлось выполнение неравенства

$$
\mathrm{K}_{\mathrm{K}}=\frac{\tau_{\max }}{\tau_{\text {пр }}}=\frac{\tau_{\max }}{\sqrt{\left(\sigma_{p}+\sigma_{n}\right)\left[2 \cdot \sigma_{p}-2 \sqrt{\sigma_{p}\left(\sigma_{p}+\sigma_{\text {сж⿱ }}\right)}+\sigma_{c \varkappa}\right]}} \geq 1
$$

$\mathrm{B}$ области растяжения предельное напряжение ограничивалось пределом прочности на растяжение:

$$
\sigma_{1}=\sigma_{\text {pacm }}
$$

Численная реализация осуществлялась методом конечных элементов в перемещениях [3] с дискретизацией рассматриваемой области на треугольные элементы первого порядка. Решение упругопластической задачи основывалось на методе начальных напряжений [4-5]. Локализация пластических деформаций в физическом смысле трактовалась как разрушение пород ВЗТ: в области сжатия - вследствие развития трещин сдвига, в области растяжения - трещин отрыва. Исходя из этих позиций, проводился анализ опасности нарушения сплошности ВЗТ под воздействием горных работ. Об- 
ласть аномального строения В3Т 1 группы учитывалась в расчетах как зона с пониженными свойствами пород.

В виду того, что в данной области все очистные работы были остановлены, выработанное пространство вдоль меридионального разреза практически отсутствует, техногенная нагрузка от соседних участков минимальна. Прогнозные расчеты показали, что формирование трещин сдвига возможно на конец процесса сдвижения и приурочено к южной границе выработанного пространства (рис. 2).

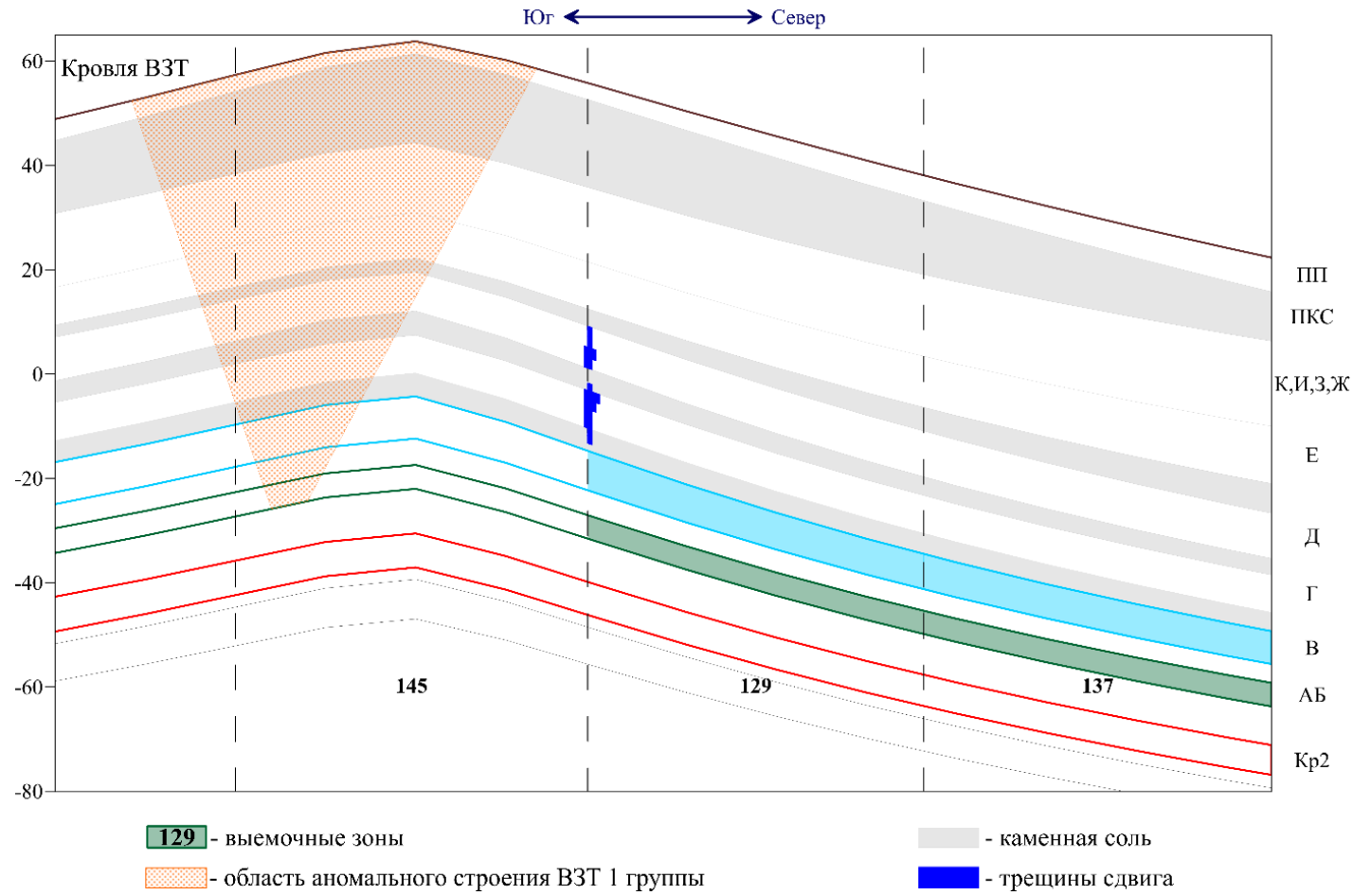

Рис. 2. Характер техногенного нарушения сплошности ВЗТ на конец процесса сдвижения
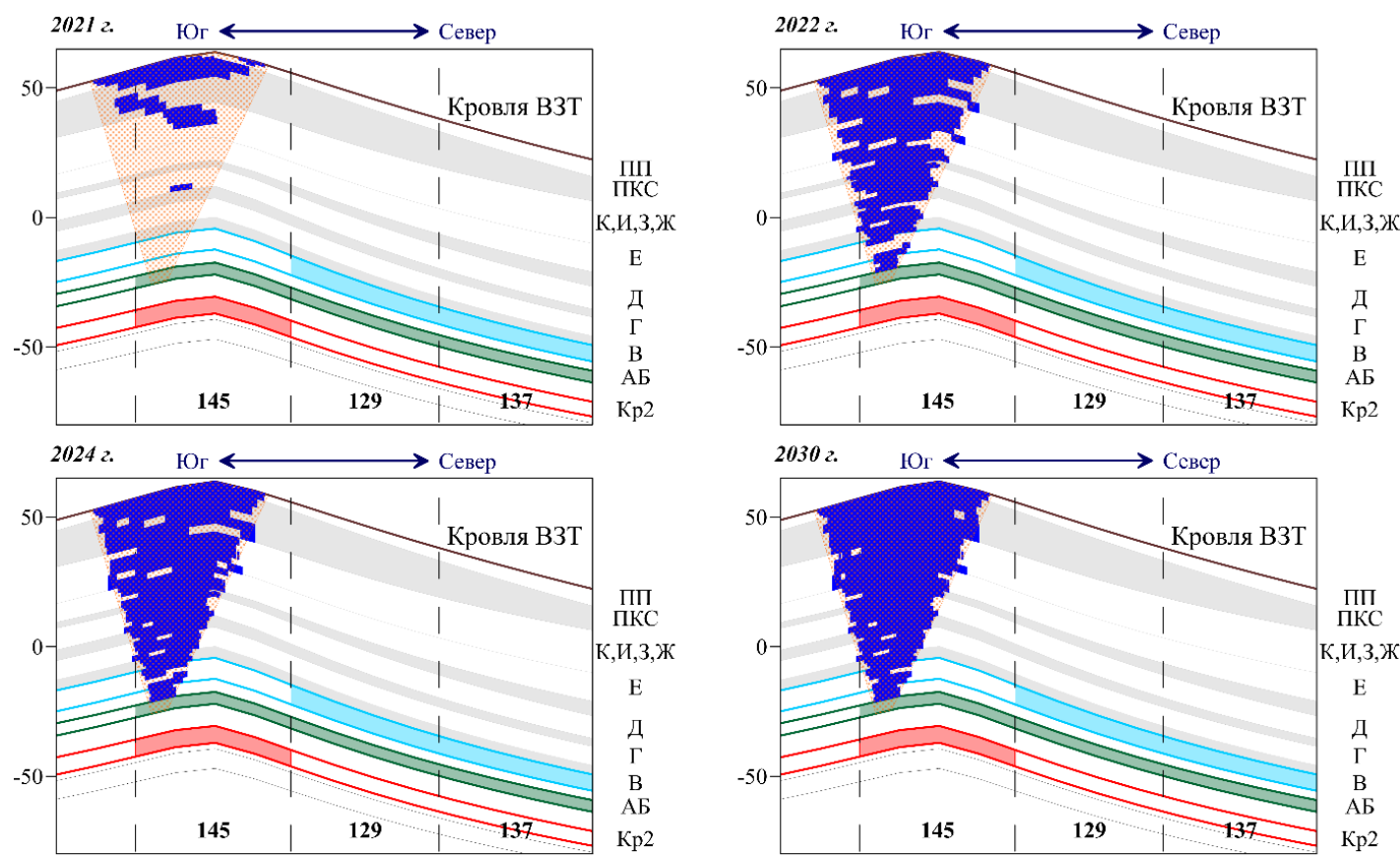

129 - выемочные зоны

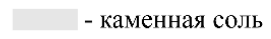

- область аномального строения В3Т 1 группы

- трещины сдвига

Рис. 3. Динамика развития техногенного нарушения сплошности ВЗТ при реализации плана горных работ 
В случае реализации плана горных работ на данном участке предполагалось отработать пласты АБ и Кр II со степенями нагружения $\mathrm{C}_{\mathrm{AБ}}$, Кр II $\leq 0.25$. В такой ситуации уже к 2021 году (рис. 3) возможно развитие трещин сдвига в верхних пластах области аномального строения В3Т. С течением времени развитие техногенной нарушенности происходит довольно стремительно и уже к 2024 году субвертикальная трещиноватость локализуется практически во всей области аномального строения водозащитной толщи. Учитывая проницаемость данной природной аномалии, можно предположить, что с нарушением первого водоупорного пласта в кровле В3Т, возможна потеря ее устойчивости целиком.

На основании проведенных геомеханических исследований установлено, что, в сложившейся ситуации, выполнение, предписанных нормативной документацией [2], мер охраны ВЗТ обеспечивает безопасность ведения горных работ вплоть до конца процесса сдвижения. Подтверждается важность проведения опережающих геологических и геофизических исследований участков, планируемых к разработке, с целью предварительного анализа и выявления возможных зон аномального строения ВЗТ.

\title{
Работа выполнена при финансовой поддержке гранта РФФИ № 18-05-00371
}

\section{БИБЛИОГРАФИЧЕСКИЙ СПИСОК}

1. Baryakh A.A., Samodelkina N.A Rheological analysis of geomechanical processes // Journal of Mining Science. - 2005. - V. 41, № 6. - P. 522-530. DOI: 10.1007/s10913-006-0015-x.

2. Указания по защите рудников от затопления и охране подрабатываемых объектов в условиях Верхнекамского месторождения калийных солей: утв. ПАО «Уралкалий», ЗАО «Верхнекамская калийная компания», ООО «ЕвроХим-Усольский Калийный комбинат». - введ. в действие 30.03.2017 в ред. 2014 г. - Пермь; Березники, 2014. - 130 с.

3. Zienkiewicz O.C. The finite element method in engineering science. - London; New York: McGraw-Hill, 1971. $-521 \mathrm{p}$.

4. Малинин Н.Н. Прикладная теория пластичности и ползучести. - М.: Машиностроение, 1975. - 400 с.

5. Фадеев А.Б. Метод конечных элементов в геомеханике. - М.: Недра, 1987. - 221 с.: ил.

УДК $539.4+519.6+622.83$

DOI:10.7242/echo.2019.4.8

\section{ТЕОРЕТИЧЕСКОЕ ОПИСАНИЕ ПРОЦЕССА РАЗРУШЕНИЯ СОЛЯНЫХ ОБРАЗЦОВ}

\author{
А.А. ЦАЮКОВ \\ Горный институт УрО РАН, г. Пермь
}

\begin{abstract}
Аннотация: Предпринята попытка описать с помощью математического моделирования экспериментально полученную кривую нагружения соляного образца кубической формы. В качестве модельной среды была взята идеальная упругопластическая модель с ассоциированным законом пластического течения и аналитическим критерием прочности, который учитывает совместное действие двух типов разрушения - сдвиг и отрыв. Трёхмерная численная реализация выполнена с помощью метода конечных элементов в перемещениях. Дискретизация области решения производилась изопараметрическими элементами гексаэдрической формы. Решение систем нелинейных уравнений выполнялось по модифицированной схеме Ньютона-Рафсона в инкрементальной форме. Для численного интегрирования пластических определяющих уравнений использовалась неявная схема алгоритма обратного отображения. Полученные результаты показали достаточное соответствие экспериментальным данным на упругом и переходном режимах деформирования образцов. Наоборот, в пластическом режиме получено полное расхождение кривых нагружения, что свидетельствует о наличие упрочняющего эффекта.

Ключевые слова: критерий прочности, упругопластические деформации, соляные породы, математическое моделирование, численное моделирование, трёхмерное моделирование, метод конечных элементов, схема Ньютона-Рафсона, алгоритм обратного отображения.
\end{abstract}

